\section{Os Pioneiros do rádio e os desafios da regulamentação da radiodifusão no Brasil dos anos 1920}

Patrícia COELHO ${ }^{1}$

Resumo: O tema do artigo é a implementação da radiodifusão no Brasil. Em 1924, um grupo de intelectuais da Academia Brasileira de Ciências organizou a Rádio Sociedade do Rio de Janeiro, sob o prefixo PRA2. Este texto analisa o trabalho destes pioneiros da radiofonia e, em especial sua participação no processo de regulamentação do broadcasting em nosso país, nos anos 1920. O texto destaca as ações, as disputas e as alianças de sujeitos aos quais a história pouco reservou espaço. Contribui com a construção de uma história da radiodifusão sob uma perspectiva plural.

Palavras-chave: Radio; Pioneiros; História; Regulamentação.

\section{Los pioneros de la radio y los desafíos de la regulación de la radiodifusión en Bra- sil 1920}

Resumen: El tema del artículo es la implementación de la radiodifusión en el país. En 1924, un grupo de intelectuales de la Academia Brasileña de Ciencias organizó la Sociedad de Radio de Río de Janeiro, bajo el PRA2 prefijo. Este trabajo analiza el trabajo de estos pioneros de la radio, especialmente la participación activa que tuvieron en el proceso de reglamentación de la radiodifusión en nuestro país en la década de 1920. El texto ilumina las acciones, conflictos y alianzas de sujetos a los que la historia algo reservado espacio. Contribuye a la construcción de una historia de la radiodifusión con una perspectiva plural

1 Professora do Departamento de Educação da PUC-Rio. Autora da tese Educadores do rádio: concepção, realização e recepção de programas educacionais radiofônicos (1935-1950), defendida na Faculdade de Educação da Universidade de São Paulo (USP), em 2012. Email: pcoelho@puc-rio.br.
Palabras clave: Radio, Pioneros; Historia; Regulación.

Nos anos 1910, Henrique Morize (1860- 1930), Manoel Amoroso Costa (1885-1928), Edgard Roquette -Pinto (1884-1954), Ferdinando Labouriau (1893-1928), Dulcídio Pereira, Álvaro Ozório de Almeida (1882-1952), Miguel Ozório de Almeida (1890-1953) e Francisco Venâncio Filho (1894-1946) todos sócios da Academia Brasileira de Ciências (ABC), militavam na causa desenvolvimento do país, por meio de investimentos na ciência e na educação. Estes homens de ciências acreditavam que os males do Brasil não haviam sido curados com inovações republicanas: voto secreto, uma nova Constituição, protecionismo às indústrias ou reformas de ensino. Tudo havia fracassado pela incapacidade do povo em compreender essas linguagens. O contexto só seria revertido por meio de um trabalho de desbravamento moral e intelectual. O termo desbravamento se associa à ideia do sertão desconhecido, ou seja, das pessoas abandonadas pelo poder público no interior.

O início da República fora marcado pelo desafio da construção de um pensamento social que transformasse conceitos por demais presentes no período monárquico (ABREU, 2010), dentre os quais a visão da maldição racial, da condenação ao atraso, e da existência de doenças que haviam degenerado o povo. A partir do contato de intelectuais com os sertões, em expedições empreendidas com as mais variadas finalidades, as populações do interior passaram a ser vistas como elementos que necessitavam do processo educacional, para serem integrados à nação ${ }^{2}$.

A partir dos resultados das pesquisas desenvolvidas na Europa, no final do século XIX, as primeiras experiências com a radiotelegrafia no Brasil foram realizadas em 1903, no Pará, por iniciativa de engenheiros da Repartição Geral dos Telegraphos.

Em 1906, Lee Forest elaborou o audion, um tipo de válvula que permitia que os sinais fracos do rádio fossem não só ampliados, mas capazes de transmitir, além do código Morse, palavras e músicas a longa distância (BURKE; BRIGGS, 2006). Tal estudo gerou outras apropriações para a radiotelegrafia. No Brasil, enquanto estudiosos dos problemas nacionais, os homens de ciências logo perceberam a importância deste veículo para vencer o isolamento.

Em 1918, sócios da Sociedade Brasileira de Ciências organizaram uma série de palestras sobre a radio-

2 São exemplos dessa empreitada os estudos de saneamento da Amazônia coordenados por Oswaldo Cruz e Afrânio Peixoto, e as obras da Inspetoria contra as secas, chefiadas por Arrojado Lisboa. Os estudos de Euclides da Cunha eram uma inspiração para novas pesquisas. 
telegrafia ultrapotente, com o objetivo de vulgarização do assunto. Os anais da instituição registram a presença de Henrique Morize, Edgar Roquette-Pinto, Manoel Amoroso Costa, Álvaro Ozorio de Almeida, o que demonstra, não apenas o papel do rádio como alvo de investimentos de suas pesquisas, como também a existência de um acompanhamento sobre os avanços dessa nova modalidade de comunicações a distância e, ainda, a promoção de amplas discussões sobre o tema.

As primeiras experiências com transmissões radiofônicas no Brasil ocorreram durante a Exposição de 1922, ocasião em que, o governo, em colaboração com as companhias americanas Western e Westinghouse, instalou duas pequenas estações transmissoras de $500 \mathrm{w}$, a saber, a primeira na Praia Vermelha e a segunda no alto do Corcovado, viabilizando assim as primeiras emissões, em parceria com a Light e com a Cia. Telefônica Brasileira. Contudo, essas comunicações públicas não podem ser consideradas como radiodifusão, tendo em vista a sua característica de recepção em espaço aberto por meio de alto-falantes, e, ainda, o número insignificante de aparelhos individuais, como nos lembra Federico (1982). Em 1923, o governo adquiriu apenas uma das emissoras, a da Praia Vermelha, para o serviço telegráfico.

Ainda em 1923, por falta de um programa de implementação de radiofonia no país, os intelectuais da Academia Brasileira de Ciências (ABC) $)^{3}$, receosos diante da possibilidade de utilização da estação da Praia Vermelha apenas para fins de telegrafia, apresentaram ao governo um projeto de radiodifusão, elaborado a partir de suas pesquisas. Naquele mesmo ano, foi fundada a Rádio Sociedade do Rio de Janeiro (PRA2) nos salões da ABC.

A PRA2 foi inicialmente presidida por Henrique Morize, que já presidia a $\mathrm{ABC}$, e sua direção ficou a cargo de Edgard Roquette-Pinto, Demócrito Lartigau Seabra, Carlos Guinle, Luiz Betim Paes Leme, Alvaro Ozório de Almeida, Francisco Lafayette, Mário de Souza e Ângelo da Costa Lima, todos sócios da ABC. Dentre os princípios traçados para a emissora, figurava a divulgação da ciência e da cultura, constando da programação números de informação, noticias de interesse geral, pequenas conferências literárias, artísticas e scientificas, números dedicados ás creanças (lições de coisas, histórias, etc.), poesias e musica vocal e instrumental (Radio, 1923, p.3).

Nella se há de procurar, ao lado das paginas consagradas ao desenvolvimento

3 Em 1921, a Sociedade Brasileira de Ciências passou a ser chamada de Academia Brasileira de Ciências, atendendo a uma convenção internacional da época. do novo meio de comunicação, tudo quanto parecer de atualidade para o progresso scientifico da pátria: $<\mathrm{RADIO}>$ - é o meio, não é o fim. Mas como é um meio ainda pouco vulgarizado, convem lembral-o a cada passo (Radio, 1923, p.6).

A concepção de radiofonia idealizada pelos intelectuais da Rádio Sociedade envolvia os campos da cultura, da educação e da instrução. Para esses pioneiros, a radiodifusão deveria dedicar-se exclusivamente à transmissão da cultura. Nesse aspecto, destacava-se a perspectiva desenvolvida por estudiosos não apenas sobre a vulgarização, como sobre a transmissão do conhecimento. Apenas o acesso ao conhecimento seria capaz de libertar nosso povo, disperso pela imensidão do território nacional, das explicações lendárias e da ignorância. A radiocultura não teria a capacidade de substituir o sistema educacional, algo muito mais complexo.

O objetivo deste artigo é analisar o processo de regulamentação da radiodifusão no Brasil, nos anos 1920. A elaboração do Decreto 16.657 foi cercada de disputas. Os pioneiros do rádio lançaram mão de estratégias para assegurar que a radiodifusão fosse regulamentada a partir dos preceitos da cultura e da ciência. É preciso perceber a introdução da radiofonia no Brasil como um movimento coletivo, resultado da fermentação intelectual que enxergava neste veículo de comunicação a solução para muitos de nossos problemas. Em assembleias, os acadêmicos definiram os caminhos da PRA2: estatutos, campanhas, aprovação de sócios e criação de seções.

\section{A PRA2 em campanha}

A instalação do estúdio Marconi, que possibilitaria o broadcasting pela Rádio Sociedade, foi aguardada durante meses após a fundação da Rádio Sociedade. Nesse interregno, era utilizada a Estação da Praia Vermelha, sob a direção da Empresa de Correios e Telégrafos, para a realização de transmissões isoladas de músicas e palestras. Isso não inibiu a intensa atividade dos sócios fundadores, que empreenderam campanhas dirigidas às autoridades em prol do desenvolvimento da radiofonia, tão prejudicada pelos seguintes obstáculos: o controle, por parte do governo, das atividades de radiotelegrafia, impedindo a aquisição de simples receptores sem autorização; os altos impostos cobrados na importação de equipamentos e as regras impostas aos que desejassem criar estações emissoras. 
As campanhas eram estratégias empregadas pelos defensores da radiofonia no Brasil em defesa dos seus pressupostos. Essas manifestações poderiam assumir diferentes formatos. Em jornais e revistas, por exemplo, os diretores da Rádio Sociedade buscavam colaboradores dispostos a contribuir mensalmente com a causa da radiofonia.

A Rádio Sociedade do Rio de Janeiro em sua campanha altruísta acceita como sócios, todas as pessoas idôneas, nacionaes ou estrangeiras, pagando apenas a insignificante quantia de $5 \$ 000$ mensais proporcionando assim horas agradáveis a todos aqueles que concorrem para o engrandecimento do país ( $O$ Botafogo, 16/5/1925, s/p).

Nestes empreendimentos, os sócios efetivos da PRA2 transmitiam a ideia de que, associando-se à emissora, as pessoas estariam colaborando com o desenvolvimento não só do rádio no Brasil, mas da própria nação, graças às atividades desenvolvidas por meio desse veículo: a pesquisa, a cultura e a educação. No olhar de Carlos Sussekind de Mendonça:

Cultos e incultos, analphabetos e letrados, sãos e doentes, fracos e fortes, sertanejos e litorâneos, cariocas e acreanos, todos vão receber, ao mesmo tempo, a ducha revigoradora que se lhes vae dar. Mais uma vez condenados a civilização, não ficará como das outras, no dilema de Euclydes da Cunha. Progredirá. Tem de progredir como se deve, pela educação, pela cultura, pelos agentes intelectuaes que, queira ou não queiram são ainda os únicos capazes de fazerem o individuo e reerguerem as nações... (Radio, 11/1923, p.9).

Em 1923, ainda não havia uma legislação que tratasse especificamente das questões do rádio. Como nos lembra Calabre (2003), nesse período, não houve tanto interesse, por parte do governo, em criar uma estrutura que propiciasse o desenvolvimento de emissoras. A lei que regulamentava as atividades de radiofonia datava de 1917, e contemplava os serviços de radiotelegrafia e radiotelefonia como um único assunto. Com a evolução tecnológica, as normas pouco atendiam às demandas que surgiam em ritmo acelerado. A necessidade de um novo regulamento era tema de debates na $\mathrm{ABC}$, que continuava compreendendo a radiofonia como foco de seus estudos.

$\mathrm{Na}$ ata de reunião da $\mathrm{ABC}$ de 20 de abril de 1923, que contou com a presença de 15 de acadêmicos, dentre os quais Miguel Ozório de Almeida e Roquette-Pinto, foram discutidas as medidas a serem tomadas por esta academia, no intuito de proporcionar o maior desenvolvimento possível da telegrafia sem fio (TSF) no país, tendo sido, para tanto, formada uma comissão composta por Roquette-Pinto, Euzebio de Oliveira e Domingos Costa.

Uma das primeiras campanhas da comissão de radiofonia da $\mathrm{ABC}$ foi empreendida em prol da criação de uma regulamentação específica para o serviço radiotelefônico nacional. A legislação de 1917 era tida como muito falha, pois respondia apenas a algumas necessidades dos amadores. Dentre os pontos considerados prejudiciais estavam: o cerceamento da liberdade dos estados, a não discriminação das atribuições dos ministérios da Marinha e da Guerra, que associavam a questão à segurança nacional, do Ministério de Viação e Obras Públicas que tratava a comunicação como serviço de utilidade pública, e as restrições impostas à indústria radiotelegráfica em geral.

Outro tópico muito debatido por esses intelectuais residia no controle exercido pelo governo sobre a recepção e a emissão, incluindo amadores em geral. $\mathrm{O}$ órgão que dispunha e legislava sobre a atuação dos meios de radiodifusão era o departamento de Correios e Telégrafos, diretamente vinculado ao Ministério da Viação, e o ouvinte, que desejasse possuir um aparelho, deveria dirigir-se aos Correios para cumprir as exigências burocráticas impostas.

A posse de aparelhos receptores era uma questão de polícia. A legislação previa que o aparelho não -registrado deveria ser apreendido, e seu proprietário conduzido ao posto policial para prestação de esclarecimentos.De acordo com o relato de Roquette-Pinto:

Naquella ocasião, além de expressamente proibida semelhante pratica, dada a má comprehensão que era tida dos verdadeiros fins e vantagens da sua generalização entre o povo. A policia apprehendia os apparelhos que descobria installados em residências particulares. O próprio estudo da radio -eletricidade encontrava por parte das

25

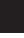


autoridades tenaz acção repressiva (O Sport, 19/4/1927, s/p)

Neste contexto, foi elaborada, em nome da ABC, uma carta ao Ministro da Viação, Francisco Sá, reivindicando a concessão de ampla liberdade para a aquisição de aparelhos receptores:

A divulgação da T.S.F., no território nacional, permittindo que um grande numero de Brasileiros se possa preparar para servir á Patria no terreno scientifico, militar, industrial, etc é uma das mais urgentes necessidades do paiz. Causa verdadeira tristeza aos estudiosos verificar o grão de inconcebível atrazo em que se encontra o Brazil, o T.S.F. como pratica popular.

Em todos os paizes do Mundo Civilizado, até mesmo nas velhas nações conservadoras do Oriente, já o Poder Publico comprehender a vatnagem de permittir amplamente a pratica usual da radiocomunicação por amadores e estudiosos. Na hora actual o surto da radiotelephonia e da radiotelegraphia e, por toda parte menos no Brasil, facto de surprehendente relevo.

A prohibição da recepção da T.S.F. é scientifica e praticamente um absurdo e um ingenuidade, si fosse possível tornal-a realmente effectiva, seria, ainda assim, um grande mal para o progresso da nação.

A vista das considerações acima, a $A B C$ julga cumprir o seu programma e trabalhar pelo bem commum fazendo um ardoroso appello a V.E. para que torne realidade tão impostantes medidas rigorosamente comprehendidas no espírito e na lettra da lei da 10 de julho de 1917 (art.12) que faculta ao Ministério da Viação conceder licença para o estabelecimento de estações experimentaes (Radio, novembro de 1923, p.39).

A previsão legislativa sobre a apreensão de aparelhos não-registrados e sobre a condução de seu pro- prietário perante a autoridade policial era considerada pelos pioneiros do rádio, como um ditame insustentável, pois inviabilizava o desenvolvimento desse tipo de comunicação entre nós. Além do documento endereçado ao Ministro Francisco Sá, havia uma campanha dirigida à população em prol da liberdade de recepção.

A campanha pertinaz e hoje victoriosa da Radio Sociedade parece ter provocado, de facto um surto de enthuziasmo entre os nossos amadores.

Há seis mezes, ninguém tinha coragem de confessar que possuía em casa um pequeno receptor. Hoje, nos bondes, nos cinemas, nos cafés até as crianças já perguntam si se ouvio Buenos Aires... Entre os symptonas promissores do surto da radiotelegraphia no Rio, é de justiça registrar, aqui, o gesto de dois amadores que se tornaram os pioneiros do broadcasting privado entre nós.

O primeiro embora um tanto roncador, tem feito algumas transmissões muito bem recebidas em toda a cidade e vae logo avisando que é a "estação do Sumaré" que falla. Nome, na verdade...

O segundo é mais nítido e modula muito melhor. No entanto, é mais modesto: não diz quem é...

De tristeza sim, porque ainda há muita gente boa que pensa que a nossa lei considera crime a pratica desse meio progressista...

Não tardará - esperemo-o dia em que, por necessidade ou por Sport todos os brasileiros possam usar o T.S.F sem receio de ver o nome na seção policial dos jornaes entre gente colhida de sorpreza (Radio, novembro de 1923, p.8)

Com o desenrolar das discussões, os intelectuais enfatizaram sua preocupação com a emissão, ou seja, o controle do tipo de informação a ser irradiada. Em um movimento inverso, os acadêmicos defendiam a rigidez nos critérios de autorização para estações emissoras. Encarnando o papel de defensores morais da sociedade, clamando pelos ideais de civilização, argumento constante no discurso da $\mathrm{ABC}$, e diante do impasse que se criara em relação aos critérios de concessão da recepção da ra- 
diofonia por parte do governo, os homens de ciência elaboraram os parâmetros objetivos que, no seu entender, seriam ideais para a solução da questão:

Experimentaes, são consideradas as estações installadas para fins scientificos, ou de ensaio de novos typos de construcção, assim como parta simples distracção, ou ainda que se chama vulgarmente de broadcasting relativos á radiotelegraphia e radiotelephonia

As estações experimentaes emissoras serão permittidas aos nacionaes idôneos pelo Ministro da Viação após requerimento transmitido por intermédio da Directoria Geral dos Telegraphos, em quer o interessado dará minuciosa descripção do apparelho que deve utilizar e do fim que tem em vista

As estações meramente receptoras serão concedidas a qualquer pessoa nacional ou extrangeira, que as requeira na Repartição Geral dos Telégraphos, mediante o pagamento de $5 \$ 000$ estampilhas

As concessões do que se denomina broadcasting, somente serão permittidas as sociedades nacionaes, legalmente constituídas e claro, se proponham exclusivamente a fins educativos, scientificos e de beneficio publico, ficarão isentas de qualquer taxa.

A qualquer broadcasting fica prohibido o uso de annuncios ou reclames commerciaes (Radio, novembro de 1923, p.41).

As sugestões retratam as bases do pensamento da maior parte dos pioneiros da radiofonia no país. Tais perspectivas se tornaram verdadeiras bandeiras por estes defendidas nas décadas de 1920 e 1930: a liberdade de recepção e o controle das transmissões para fins científicos, culturais e educativos.

Como parte da campanha destinada a influenciar a elaboração da legislação que regulamentaria o serviço de radiofonia, foi realizado um inquérito, durante o qual políticos e intelectuais foram convidados a dar suas opiniões sobre o que deveria ser modificado no Decreto de 1917. Os diferentes pontos de vista expostos servem para ilustrar a polêmica gerada pela questão. A primeira opinião publicada em Radio foi manifestada por Prudente de Moraes, deputado e professor de Direito da Universidade do Rio de Janeiro que, sugeriu que a nova legislação devesse cercear a liberdade dos amadores em suas casas postos de radiotelephonia.

É esclarecedor o olhar de Dulcídio Pereira, então chefe da Comissão de broadcasting da Rádio Sociedade, sobre a liberdade de transmissões de programas:

Aos que desejam apenas irradiações, sem caracter de broadcasting, restrinjamos de muito a zona permittida no spectro do rádioelectrico, não lhes deixemos ir além das ondas de cem metros, e sejamos nesse particular extremamente rigorosos na fiscalização. Exijamos; mesmo dos amadores que irradiem, muitos requisitos, entre os quais a idoneidade moral e a pratica de recepção dos signaes Morse devem ser essenciaes. Ondas maiores só devem ser permitidas ás associações de radiocultura, com intuitos perfeitamente definidos, onde a permanência de mentalidades reconhecidamente idôneas, seja a maior garantia da excellencia dos seus broadcastings como meio educativo, maio justificativo da liberdade de irradiar em ondas grandes (PEREIRA, Radio, 1/07/1924, p.18).

Ainda vivendo na era do rádio quase como se tratasse de um advento científico, a maior oposição à liberdade de recepção, neste período, foi manifestada pelo próprio governo, que não abria mão deste tipo de controle. Como já havia afirmado, vivia-se sob o impacto da Primeira Guerra Mundial, e se enxergava no rádio o risco de utilização do veículo como instrumento de espionagem, para a transmissão de informações aos países inimigos. Tal receio era compartilhado por outras nações. Outro fator destacado por Gilioli (2008) foram os movimentos da década de 1920 no Brasil, como, por exemplo, a Revolução de 1924 e a Coluna Prestes, que despertaram nas autoridades o receio de uso da radiofonia como veículo de propaganda revolucionária.

Nesse aspecto, e bem provável que a participação, em levantes tenentistas, de certos fundadores da Rádio Sociedade como, por exemplo, Ferdinando Labouriau e Mario Brito, tenha acirrado o temor do governo 
quanto ao potencial do rádio na propagação de ideais políticos. A publicação do decreto que passaria a regulamentar esse tipo de comunicação foi por várias vezes adiada. Previsto para entrar em vigor no início de 1924, depois de ampla discussão, ele só veio a ser publicado no final daquele ano. Questionado sobre os motivos da demora, Manoel Ayres, funcionário do Departamento de Telegraphos, respondeu à Radio:

Examinando bem, essa liberalidade é mais uma questão de palavras do que outra qualquer coisa. Não há duvida nenhuma que em relação ás leis inglezas e allemãs, ela offerece vantagens sob esse ponto de vista, não cria monopólios, não estabelece privilégios... Mas francamente, nós também não temos isso? Que querem os senhores que se faça no Brasil? Que não se cobre taxas ás estações receptoras? É impossível. Toda utilização de meios de communicação é paga. Não se conhece excepção a esse respeito. Os paizes mais liberaes a consignam maior ou menor até, mas sempre existe. Que se permitta a transmissão a todos, sociedades e particulares? Mas isto seria um inferno!

Não há regulamento novo para ser publicado.

(Rádio, fevereiro de1924, p.34).

Em busca de apoio, a campanha pela difusão do TSF, promovida pela Radio Sociedade se estendeu a outros estados, chegando a abranger todo o território nacional. Forma enviados convites de viagens aos amadores, para que estes pudessem conhecer as instalações da PRA2. As adesões à causa eram enaltecidas:

Eterno vanguardeiro de todas as iniciativas úteis que se levam a effeito no Brasil em beneficio da coletividade, a campanha brasileira pela Radiocultura sentia, na verdade, a falta desse estímulo vivificador das energias paulistas.

Eil-o, porém que chega agora, com a fundação da "Sociedade de Radio Telephonia do Estado de São Paulo”. (Radio, novembro de 1923, p7).
Sob outro ângulo, a campanha da Rádio Sociedade reivindicava, ainda, a diminuição dos impostos incidentes sobre os equipamentos radiofônicos, o que os tornava extremamente caros. Contudo, o discurso revela olhares mais amplos e, novamente, nos fornece indícios da interseção construída entre o rádio, a ciência e a educação:

Uma difficuldade, que já poderia estar há muito tempo resolvida entre nós é esta dos direitos fantásticos que cobra nossa alfândega á importação do material scientifico de toda natureza.

Todos os dias os maiores responsáveis pela nossa cultura clamam contra o ensino theorista que as escolas nos ministram, protestando pela necessidade immediatta da sua conversão aos moldes práticos com que elle é feito em todo o mundo. Os projectos de reforma estão cheio de palavras bonitas a este respeito. Os discursos de projectos de reforma (Radio, 11/1923, p.8)

A mobilização junto ao governo trouxe bons frutos, representados pela isenção de impostos dos equipamentos para a montagem da estação, o que comprova a força das campanhas junto ao poder constituído:

Continuando a boa vontade do Governo em face do desenvolvimento crescente do T.S.F. no Brasil o Sr Ministro da Fazenda acaba por isentar de todos os impostos o despacho da estação typo Marconi, que conforme noticiamos, foi offerecida pela Companhia Radiotelegraphica Brasileira para os serviços de broadcasting na Radio Sociedade (Radio, 12/1923, p.5).

\section{Enfim, o Decreto 16.657}

O decreto 16. 657, tão esperado pelos intelectuais da Rádio Sociedade do Rio de Janeiro, foi publicado em 5 de novembro de 1924. O teor de seus artigos demonstrou o êxito parcial das campanhas empreendidas pelos pioneiros da radiofonia no Brasil.

Uma das principais reivindicações dos incentivadores da radiodifusão no Brasil nos anos 1920, a saber, 
as irradiações dedicadas exclusivamente a disseminação da cultura e da ciência, foram contempladas no artigo 51: "A difusão radiotelephonica (broasd-casting) só será permittida ás sociedades nacionaes, legalmente constituídas, que se proponham exclusivamente a fins educativos, scientíficos, artísticos e de benefício publico e serão isentas de qualquer taxa". (Brasil, Decreto 16.657, de 5 de novembro de 1924)

A isenção de taxas para difusoras representava uma vitória apenas parcial. As emissoras foram beneficiadas com a isenção de impostos para emissão. Para os ouvintes, no entanto, a campanha não surtiu os mesmos efeitos benéficos. É muito comum a referência nos jornais ao alto custo da aparelhagem, devido aos vários impostos de importação sobre ela incidentes. Nas revistas especializadas também há muitas orientações aos radioamadores acerca de materiais que pudessem baratear os equipamentos receptores.

Os anúncios vistos com desconfiança pelos diretores da PRA2, não foram vedados pelo Decreto. O primeiro parágrafo do artigo 51 previa que apenas deveriam ser previamente autorizados pelo governo: "O Governo reserva para si o direito de permitir a transmissão a radiotelephonica (broadcasting) de anúncios e reclames comerciais (Brasil, Decreto 16.657, de 5 de novembro de 1924). Os dirigentes da Rádio Sociedade do Rio de Janeiro entendiam que a veiculação dos anúncios poderia comprometer os fins culturais que deveriam nortear as emissoras.

As irradiações com caráter político foram taxativamente coibidas na legislação: "É inteiramente prohibido propagar por broadcasting sem permissão do governo, notícias internas de caracter político" (Brasil, Decreto 16.657, de 5 de novembro de 1924).

Na década de 1920, o mundo vivia as consequências da Primeira Guerra Mundial. Uma das questões que atormentavam os homens de ciência consistia no uso da tecnologia para prejudicar a humanidade, como ocorrera com a dinamite e com o avião. O próprio sistema de radiotelefonia era visto como uma arma de guerra, pois serviu à troca de informações para ataques e à divulgação de idéias subversivas ao governo. Nos Estados Unidos e na Inglaterra a radiodifusão amadora foi proibida por motivos militares (BURKE; BRIGGS,2006).

Sobre o assunto, o artigo 64 previa que: "Em caso de guerra ou de convulsão política, ou sempre que o interesse nacional o exigir, poderá o Governo suspender o funcionamento de qualquer funcionamento de estação particular, ou occupal-a para seu serviço e cassar qualquer concessão feita" (Brasil, Decreto 16.657, de 5 de novembro de 1924).
O Decreto contemplava outras formas de controle que alteravam a rotina de trabalho das emissoras e interferiam nas expectativas dos ouvintes.

Um bom exemplo desta assertiva reside nas restrições à idiomas estrangeiros conforme estipulado no artigo 50:

\begin{abstract}
São prohibidas todas as emissões moduladas pela palavra, que não forem feitas em linguagem clara e em portuguez, salvo autorização especial, em casos especiaes, para uso de idioma estrangeiros, bem assim todas as emissões feitas por processos que não permitirem a recepção e a compreensão das mensagens, por meio de aparelhos receptores, para esse fim adoptados pela Repartição Geral dos Telegraphos (Brasil, Decreto 16.657, de 5 de novembro de 1924).
\end{abstract}

A radiodifusão era vista pelos pioneiros como um estreitamento dos laços de amizade entre os países, e, desta forma, como meio para a mitigação do clima de inimizade entre os povos. Por outro lado, o rádio ainda se achava na fase do encantamento com o equipamento. $\mathrm{O}$ que realmente chamava a atenção dos amadores, muito mais que a programação, consistia na possibilidade de ouvir sons de lugares distantes, e na preocupação em melhorar a performance da aparelhagem. As crônicas sobre os radio-ouvintes fazem transparecer este aspecto :

O rádio só é perverso quando a gente está com
visitas. Não há meio de se apanhar nada! Mal
a visita a visita vae embora, ouve-se tudo. Nova
Zelandia, KDKA, Londres, Torre Eiffel.
Buenos Aires, então é sopa! Pelo menos é isso
que nos dizemos no dia seguinte ás visitas de
véspera (Radio, maio de 1926, p.33).

A oportunidade de acesso a estações internacionais causava tanto entusiasmo entre os ouvintes que as revistas publicavam tabelas com os horários durante os quais seria possível a captação de um sinal de recepção mais nítido.

29

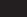




\section{Estações argentinas e seus horarios \\ (BROADCASTING) \\ HORA BRASILEIRA}

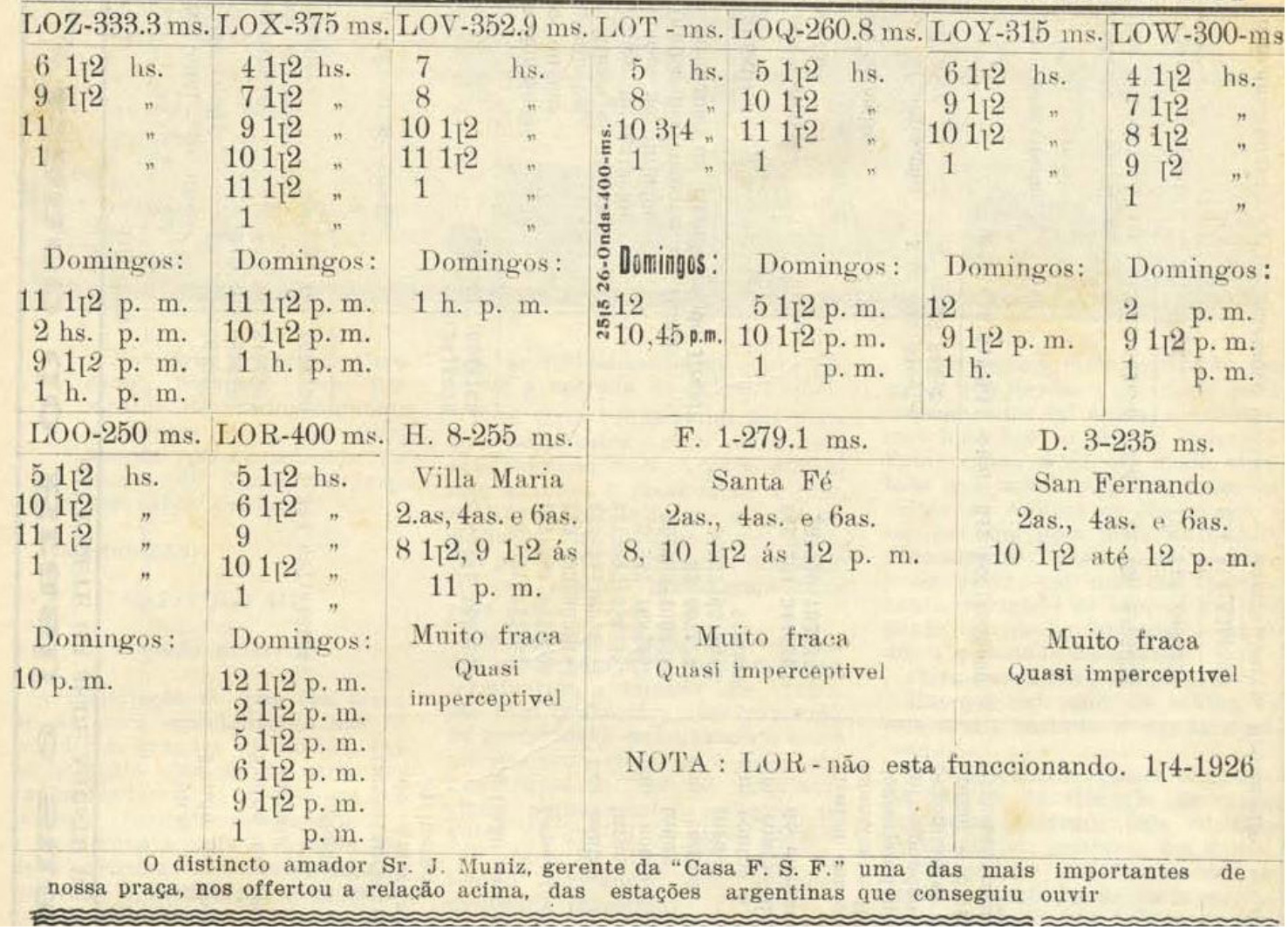

(Radio, novembro de 1926, p.14)

O artigo 63 assegurava o controle por meio de inspeções: "Todas as estações particulares, emissoras ou receptoras, serão inspecionadas pela Repartição Geral dos Telegraphos, todas as vezes que julgar conveniente". (Brasil, Decreto 16.657, de 5 de novembro de 1924).

\section{As Sociedades de radio e seus estatutos}

Após a publicação do Decreto 16.657, os Estatutos da Radio Sociedade de Rio de Janeiro foram aprovados em assembleia-geral de sócios efetivos, realizada em 1 de maio de 1926. Composto por 20 artigos, este documento tinha por objetivo regulamentar o funcionamento da emissora após a fase de sua implementação: "Hoje a Radio Sociedade é uma força na consciência nacional. É uma força moral, intelectual, e até mesmo econômica pelo patrimônio que possue pelo movimento financeiro que tem e mais ainda pelo movimento financeiro que promove Brasil a fora" (Estatutos da Radio Sociedade do Rio de Janeiro, 1926, p.11)

A Rádio Sociedade e a Estação Praia Vermelha não brilhavam mais sozinhas no cenário nacional. Havia outras emissoras em funcionamento como, por exemplo, a Rádio Club do Brasil, a Rádio Educadora Paulista e a Rádio Club de Pernambuco, que também adotavam os preceitos de transmissão da cultura sem o caráter de comercial. Não se observava qualquer clima de concorrência, e nem caberia tal rivalidade, pois todas lutavam pelo desenvolvimento da radiofonia nacional. Sempre que possível, havia troca de informações, e há até mesmo registros de visitas aos estúdios por associados de diferentes rádios. A PRA2 disponibilizava aos associados de outros estados os mesmos direitos atribuídos aos seus sócios.

A própria PRA2 já dispunha de uma estrutura bem mais complexa que a da fundação. Havia diferentes seções como Broadcasting, Organização de programas e Artística. $\mathrm{Na}$ sede da emissora, a biblioteca contava com mais de 800 volumes, além de esquemas sobre radiofonia para livre consulta. Nas salas de laboratório, eram realizados cursos de radiotelegrafia e radiotelefonia com aulas práticas em transmissores menos potentes, doados por sócios. Eram realizadas as primeiras experiências sobre a transmissão com o uso de ondas curtas, embora sem muito sucesso.

Diante das aceleradas mudanças ocorridas no mundo da radiofonia, os Estatutos da Radio Sociedade 
do Rio de Janeiro eram uma estratégia dos seus sócios efetivos não apenas para reafirmar os preceitos da radiodifusão voltada à cultura e a ciência, como também para evidenciar que o funcionamento da emissora dentro dos parâmetros estabelecidos pelo Decreto. A propósito, cabe aludir ai seu Artigo 3․ A Radio Sociedade fundada com fins exclusivamente scientificos, technico, artísticos e de pura educação popular, não se envolverá jamais em nenhum assumpto de natureza profissional, industrial ou politica, ajuda dimensionar a militância praticada na PRA2 por um controle e uma padronização da radiodifusão em torno dos ideais educativos. Esse setor da intelectualidade acreditava ser incumbido da missão de assegurar a radiofonia livre das leituras nocivas, garantindo, assim, a construção de uma cultura homogênea.

Ao prever a isenção de responsabilidade da Rádio diante de possíveis atos isolados de seus sócios, o artigo 18 do Estatuto reforça a intenção dos dirigentes da PRA2 de manter a imagem da emissora afastada de movimentos políticos, que poderiam prejudicar ou inviabilizar seu funcionamento: "A Radio Sociedade não assume responsabilidade por quaisquer actos praticados por seus membros, fora dos que estiverem dentro das normas de seus estatutos e forem de acordo com eles claramente autorizado"(Estatutos da Radio Sociedade do Rio de Janeiro, 1926). Neste aspecto, é possível observar a concepção esposada por estes homens de rádio, no sentido de que as irradiações eram muito mais eficazes que movimentos políticos isolados. A transmissão da cultura ao povo era uma arma mais eficiente para o desenvolvimento do país.

Ao final da década de 1920, o cenário começou a mudar, pois outras questões vieram a desafiar os homens do rádio: a necessidade da renda dos reclames comerciais para o pagamento das despesas das emissoras, a reivindicação dos artistas quanto ao pagamento de um adicional por ocasião da irradiação de suas obras e a criação de rádio-escolas.

Diante do alto custo da emissora e as escassas fontes de renda, a diretoria recorreu ao serviço de publicidade. Ao justificar esta decisão, os diretores, embora ressaltassem serem contrários à exploração comercial da rádio, tiveram de aderir aos reclames por tratar-se do meio encontrado para financiar o propósito do rádio disseminador da cultura e da ciência. No ano de 1926, é possível observar que o anúncio de alguns programas vem acompanhado de suas respectivas patrocinadoras: Transmissão da opera cantada no Teatro São Pedro do Rio de Janeiro, pela Companhia Lyrica da Empresa Paschoal Segreto.

Uma vez aprovado pelo Ministério da Viação e Obras Públicas, o estatuto da Rádio Sociedade acabou sendo transformado em um modelo para as demais emissoras que pleiteavam uma autorização para iniciar seus trabalhos. Para a criação de seu regulamento, em 1926, a Rádio Sociedade Mayrinck Veiga usou a mesma redação do estatuto da PRA2.

Em 1926, os sócios efetivos da Rádio Sociedade publicaram em Electron o artigo intitulado Uma explicação necessária onde relatavam as várias dificuldades enfrentadas pela PRA2 enfrentava, e, principalmente, a falta de recursos financeiros:

Saibam, pois os que não conhecem esses esforços que, para a música, a noção scientifica, a informação diária dos acontecimentos mundiaes e a informação comercial, tão útil ao interior do paíz, lhes cheguem aos lares é preciso manter-se uma aparelhagem custosa e a organização de programmas diários também custosos.

A nossa aparelhagem obtida por meio de esforços formidáveis, representa um valor de seis mil libras esterlinas e sua montagem custou cem contos de réis.

Mas essa aparelhagem technica, com o continuo funcionamento da nossa estação, deprecia-se, gasta-se, exige substituição de peças, de válvulas impõe cuidados esmerados de conservação, dada a delicadeza de suas peças. Basta lembrar que trabalhamos, só na estação transmissora, com oito grandes válvulas de transmissão cujo preço médio é de 30 libras cada uma cuja duração media é de mil horas e que estão sujeitos a accidentes de toda sorte (Electron, agosto de 1926, p.)

Diante do novo contexto que emergia ainda nos final dos anos 1920, a década seguinte não viria a ser marcada pela discussão de questões técnicas ou pela luta pela autorização indiscriminada para a recepção. Várias empresas que trabalhavam com equipamentos para radiofonia, tais como receptores e peças, acabariam por montar suas emissoras, com interesses amplamente comerciais, a partir da tecnologia disposta pela Estação Sepetiba. A luta dos homens pela ciência, pela educação e pelo rádio se desloca para o controle do que deve ser irradiado, uma vez que tais intelectuais se sentem responsáveis pela condução da cultura nacional. Tanto assim é que não aceitam 
perder o controle sobre o veículo de comunicação que tanto divulgaram como solução para o nosso atraso.

\section{Por uma história do rádio}

Pouco sobrou do mundo do rádio na década de 1920. Ao levantar obras sobre o tema, é possível perceber a escassez dos testemunhos de homens que viveram essa época e que se propuseram a organizar sua memória. Renato Murce (1976), com Bastidores do rádio, e Luiz Carlos Saroldi (1984), com Rádio Nacional o Brasil em sintonia são raros exemplos dessa iniciativa. Poucos registros orais foram preservados, seja pela limitação financeira das rádios, que impunha a reutilização das fitas e a eliminação de gravações anteriores, seja pela dificuldade técnica na conservação do material. Os arquivos de pessoas que atuaram nesse mundo radiofônico, ainda que abertos ao público, encontram-se em fase de tratamento. É o caso de Roquette-Pinto, ícone da história do rádio, cujo arquivo está localizado no Centro de Memória da Academia Brasileira de Letras.

Apesar da fragmentação dos arquivos, que dificultam bastante o trabalho dos pesquisadores, é possível construir novas visões para história do rádio, que superem o memorialismo. É importante conferir destaque a homens que apesar de terem atuado expressivamente no processo de implementação da radiofonia, desfrutam de pouco espaço na história.

Ao analisar a regulamentação do broadcasting no Brasil, ocorrida nos anos de 1920, conhecemos a atuação de homens de ciências, que acreditavam que este veículo de comunicação traria progresso ao nosso país.

Enxerguei o processo de implantação da radiofonia no Brasil como um projeto coletivo que percorreu por várias etapas. Em um primeiro momento, se assemelhava a um grande laboratório, onde foram criadas as emissoras como, por exemplo, a Radio Sociedade do Rio de Janeiro e a Rádio Club, por iniciativa de intelectuais, desejosos que as irradiações se tornassem uma realidade no cotidiano dos brasileiros, por enxergarem no potencial de comunicação deste veículo a solução para a ignorância, as doenças e a miséria que acometiam a população. Nos seus estúdios, estes homens de ciência compartilhavam suas experiências, vulgarizavam o conhecimento científico por meio de palestras e debatiam suas ideias. Para compreender a complexidade deste contexto, foi preciso esmiuçar a trajetória de sujeitos que pouco se dedicaram à construção de uma memória associada à radiofonia, ainda que muito tenham colaborado para o seu desenvolvimento: Dulcídio Pereira, Miguel
Ozório de Almeida, Álvaro Ozório de Almeida e Ferdinando Labouriau. Desta forma, me distanciei de uma visão muito presente em nossa historiografia, de que a radiodifusão nacional foi uma obra individual de Edgard Roquette-Pinto.

Ao estudar a correspondência, os periódicos, a legislação, os ofícios e as atas de reuniões dispersas em vários arquivos, procurei preencher as lacunas que dificultavam a compreensão das disputas protagonizadas pelos pioneiros do rádio. Estes defensores da ciência partilhavam a concepção de que o caminho para o desenvolvimento da nação permeava a ciência, a educação e o rádio. Juntos fundaram a Academia Brasileira de Ciências, a Associação Brasileira de Educação, e a Rádio Sociedade do Rio de Janeiro, e se encarregaram da administração da Rádio Club. Embora fossem partidários de diferentes perspectivas sobre a necessidade de uma regulamentação legal para a atividade, partilhavam o entendimento de que deveriam haver formas de controle do conteúdo irradiado. Eis aí, em síntese, a descrição das disputas, dilemas, discordâncias, e incoerências presentes em qualquer trajetória.

\section{Referências bibliográficas:}

ABREU, Regina. Colecionando o outro: o olhar antropológico nos primeiros anos da República do Brasil. In: HEIZER, Alda; VIDEIRA, Antonio Augusto Passos (org.). Ciência, Civilização e República nos Trópicos: 18891930. Rio de Janeiro: Mauad X: Faperj, 2010.

BURKE, Peter, BRIGGS, Asa. Uma história da mídia: de Gutenberg à internet. 2 ed. Ver. e ampl. Rio de Janeiro: Zahar,2006.

CALABRE, Lia. Políticas públicas culturais de 1924 a 1945: o rádio em destaque. Estudos Históricos, n 31, 2003/1.

COELHO, Patrícia. Educadores do rádio: concepscão, realização e recepção de programas educacionais radiofónicos: Faculdade de Educação da Universidade de São Paulo (USP), 2012. Tese de Doutorado.

FEDERICO, Maria Elvira Bonavita. História da comunicação. Rádio e TV no Brasil. Petrópolis, Vozes, 1982.

GILIOLI, Renato de Sousa Porto. Educação e cultura no rádio brasileiro: concepscoes de radioescola em Roquette-Pinto: Faculdade de educação da Universidade de São Paulo (USP), 2008. Tese de doutorado. 


\section{Fontes primárias}

Radio (Revista de divulgação scientífica-geral especialmente consagrada a Radio-cultura). Rio de Janeiro. Outubro de 1923, p.1.

Radio (Revista de divulgação scientífica-geral especialmente consagrada a Radio-cultura). Rio de Janeiro. Novembro de 1923, p.39.

Radio (Revista de divulgação scientífica-geral especialmente consagrada a Radio-cultura). Rio de Janeiro. Dezembro de 1923, p.5.

Brasil, Decreto 16.657,

O Botafogo, 16/5/1925.

O Sport, 19/4/1927.

Recebido: 30/09/2013

Aprovado: 03/11/2013 